\title{
ASSESSMENT OF IMPACT OF TRAINING ON KNOWLEDGE OF ANGANWADI WORKERS OF DISTRICT LUDHIANA, PUNJAB: PRE AND POST TRAINING EVALUATION
}

\author{
Urvashi' ${ }^{1}$ Anurag Chaudhary22, Sarit Sharma ${ }^{3}$, Sangeeta Girdhar 4 , Mahesh Satija ${ }^{5}$, Pushapindra Kaushal ${ }^{6}$, Jasneet Chawla ${ }^{7}$ \\ 1 Post Graduate Resident, Department of Community Medicine, Dayanand Medical College \& Hospital, Ludhiana, Punjab. \\ 2 Professor \& HOD, Department of Community Medicine, Dayanand Medical College \& Hospital, Ludhiana, Punjab. \\ 3 Professor, Department of Community Medicine, Dayanand Medical College \& Hospital, Ludhiana, Punjab. \\ ${ }^{4}$ Professor, Department of Community Medicine, Dayanand Medical College \& Hospital, Ludhiana, Punjab. \\ ${ }_{5}^{5}$ Associate Professor, Department of Community Medicine, Dayanand Medical College \& Hospital, Ludhiana, Punjab. \\ ${ }^{6}$ Associate Professor, Department of Community Medicine, Dayanand Medical College \& Hospital, Ludhiana, Punjab. \\ 7 Intern, Department of Community Medicine, Dayanand Medical College \& Hospital, Ludhiana, Punjab.
}

\section{ABSTRACT}

\section{BACKGROUND}

Anganwadi Workers (AWWs) are recruited under Integrated Child Development Services (ICDS) scheme for a population of 400$800 \mathrm{in} \mathrm{rural/urban}$ areas and 300-800 in tribal areas. The key functions of AWWs include nutrition and health education, growth monitoring, health check-ups, assisting ANMs in provision of health care services, immunization and referral services. The output of the ICDS scheme is to a great extent dependent on the knowledge of AWW. This study is aimed to assess the knowledge of AWWs regarding comprehensive health care of children and to evaluate the impact of the training programme on their knowledge.

\section{METHODS}

The study was carried out at the Urban Health Centre, Shimlapuri, Dayanand Medical College and Hospital, Ludhiana, Punjab. Anganwadi workers were imparted training regarding various services rendered by them. The impact of training was evaluated by comparing the pre- and post-test knowledge of AWWs. A pre-tested proforma was administered to the AWWs before and after the training. It consisted of 15 questions related to different aspects of functions of AWWs. The data was then analysed using statistical techniques like mean, Standard Deviation and t-test.

\section{RESULTS}

The 15 questions proforma was grouped under 6 categories. The mean pre-test score was observed to be $8.3 \pm 2.5$ and the mean post test score was 10.6 \pm 2.3 . ( $p=0.000)$. Improvement in knowledge was seen in all categories of questions, which included health care services, immunization, nutrition and health education, health check-ups, growth monitoring and referral services.

\section{CONCLUSIONS}

The findings of present study suggest that knowledge of AWWs significantly improved after the training. Thus, refresher training programmes should regularly be conducted for improving the knowledge of grass-root level health workers to ensure provision of good quality services.

\section{KEYWORDS}

Impact, Training, ICDS, Anganwadi Workers.

HOW TO CITE THIS ARTICLE: Urvashi, Chaudhary A, Sharma S, et al. Assessment of impact of training on knowledge of Anganwadi workers of district Ludhiana, Punjab: pre and post training evaluation. J. Evolution Med. Dent. Sci. 2016;5(11):462-465, DOI: $10.14260 /$ jemds/2016/106

\section{INTRODUCTION}

The most valuable asset of a nation is its human resource. Countries who have learned to invest in its human resources are today the most progressive and developed nations. Realizing this Government of India launched Integrated Child Development Services (ICDS) program on $2^{\text {nd }}$ October 1975 for the overall development of children who constitute the most precious asset of country's future.

Financial or Other, Competing Interest: None.

Submission 24-12-2015, Peer Review 19-01-2016,

Acceptance 25-01-2016, Published 05-02-2016.

Corresponding Author:

Urvashi,

Room No. 2009, Junior Doctor's Hostel,

Christian Medical College \& Hospital,

Ludhiana, Punjab.

E-mail: urvashi9kataria9@gmail.com

DOI: $10.14260 /$ jemds/2016/106
ICDS program has operated satisfactorily since more than three decades of its existence.[1] It is India's response to the challenge of providing pre-school education on one hand and breaking the vicious cycle of malnutrition, morbidity, reducing learning capacity and mortality on the other.[2] It delivers services right at the doorsteps of the beneficiaries to ensure their maximum participation. ${ }^{[3]}$

The rich experience of ICDS has brought about a welcome transition from welfare orientation to a new challenging perspective of social change. Being the world's largest outreach programme, targeting infants and children below 6 years of age, expectant and nursing mothers, ICDS has generated interest worldwide amongst academicians, policy makers, planners, administrators and those responsible for implementation. ${ }^{[4]}$

In ICDS program, AWW assumes a pivotal role due to her close and continuous contact with the beneficiaries. The key functions of AWWs include imparting non-formal pre-school 
education to children in age group 3-6 years and nutrition and health education (NHED) to women in the age group 15-45 years, growth monitoring, health check-ups assisting ANMs in provision of health care services, immunization and referral services. The output of the ICDS scheme is to a great extent dependent on the knowledge of AWWs. Taking into consideration all the above factors, this study was conducted to assess the knowledge of AWWs regarding comprehensive health care of children and to evaluate the impact of the training programme on their knowledge.

\section{MATERIAL AND METHODS}

The study was carried out at the Urban Health Training Centre of Dayanand Medical College and Hospital (DMC and H), Ludhiana, Punjab. Government of Punjab and Baba Farid University of Health Sciences, Faridkot, planned to train all the AWWs of Punjab on the various aspects of the services rendered by them. Selected faculty members from all the Medical Colleges of Punjab were trained as trainers during the central training held at the University. After being trained, training was held for AWWs in April by the faculty of Department of Community Medicine, DMC and H, Ludhiana, which continued up to mid-September.

The AWWs were trained regarding various aspects of the services rendered by them to the beneficiaries. A total of 41 training sessions were held. The knowledge of AWWs was tested by administering a pre-designed, pre-tested proforma before the training. The proforma was designed so as to contain questions on every aspect of the services provided through the Anganwadi Centre. It was translated to local language (Punjabi) by the head of Punjabi Department of Govt. Girls College, Ludhiana. It was validated by doing pilot study on 20 Anganwadi workers during the first training session and necessary changes were made.

The sample size required for the study was calculated as follows:

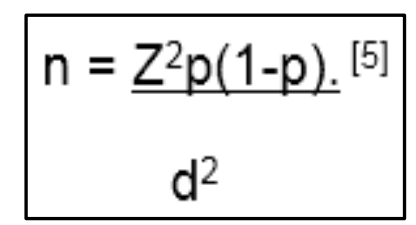

Where

$\mathrm{n}=$ Sample size

$\mathrm{p}=$ Expected prevalence or proportion

$\mathrm{d}=$ Precision rate
Hereby taking,

$Z=1.96$ (Approx. = 2, for level of confidence of 95\%)

$\mathrm{p}=0.5$ Considering knowledge of AWWS as $50 \%$ to obtain the maximum sample size $\}$

$\mathrm{d}=0.05$

Hence, $n=384$.

So, a total of $400 \mathrm{AWW}$ sere included in the study.

By adopting simple random sampling technique, 10 AWWs were selected per training session, but 23 proformas were found to be incompletely filled at the time of data analysis. So, final analysis was done on 377 completed pre- and posttraining proforma.

The scores were calculated based on the responses to a proforma containing 15 questions. One mark was given for a correct response, while no mark was given for a wrong response. The knowledge of each AWW was scored out of 15. The impact of the training was evaluated by comparing the pre and post training scores. It was made sure that the proformas were filled individually by the AWWs under the direct observation of the trainers. The proformas were then analysed by using SPSS software version 20 using statistical techniques like mean, Standard Deviation and t-test.

The study was duly approved by the Institutional Ethics Committee of Dayanand Medical College and Hospital, Ludhiana.

\section{RESULTS}

The 15 questions proforma was grouped under 6 categories viz. health care services; immunization; nutrition and health education; health check-ups; growth monitoring and referral services. Amongst the different services provided by AWWs, they had best knowledge about the component of growth monitoring (83.0\%) and least about immunization (27.3\%). (Table 1) It was observed that $62.3 \%$ of AWWs had a knowledge assessment score of above $50 \%$ as per the proforma provided. The proportion of AWWs having a knowledge assessment score of above $50 \%$ increased to $90.2 \%$ after the training (Table 2).

The mean pre-test score was observed to be $8.3 \pm 2.5$ and the mean post test score was $10.6 \pm 2.3$. ( $p=0.000)$ (Fig. 1) Improvement in knowledge was seen in all categories of questions which included health care services; immunization; nutrition and health education; health check-ups; growth monitoring and referral services (Fig. 2).

\begin{tabular}{|c|c|c|c|c|c|c|}
\hline $\begin{array}{l}\text { Type of } \\
\text { Service }\end{array}$ & $\begin{array}{l}\text { No. of } \\
\text { ques }\end{array}$ & $\begin{array}{l}\text { Total no. of } \\
\text { questions } \\
\text { asked }\end{array}$ & $\begin{array}{l}\text { Total no. of } \\
\text { correct responses } \\
\text { in pre test }\end{array}$ & $\begin{array}{l}\text { Total no. of } \\
\text { correct responses } \\
\text { in post test }\end{array}$ & $\begin{array}{l}\text { Chi } \\
\text { sq }\end{array}$ & P-value \\
\hline $\begin{array}{l}\text { HEALTH CARE } \\
\text { SERVICES }\end{array}$ & 2 & $\begin{array}{c}754 \\
(377 \times 2)\end{array}$ & $\begin{array}{c}595 \\
(78.9)\end{array}$ & $\begin{array}{c}668 \\
(88.6)\end{array}$ & 25.26 & $<0.001$ \\
\hline IMMUNIZATION & 2 & $\begin{array}{c}754 \\
(377 x 2) \\
\end{array}$ & $\begin{array}{c}206 \\
(27.3)\end{array}$ & $\begin{array}{c}437 \\
(57.9)\end{array}$ & 143.4 & $<0.001$ \\
\hline $\begin{array}{c}\text { NUTRITION \& } \\
\text { HEALTH EDUCATION }\end{array}$ & 4 & $\begin{array}{c}1508 \\
(377 \times 4) \\
\end{array}$ & $\begin{array}{c}710 \\
(47.08)\end{array}$ & $\begin{array}{c}1032 \\
(68.4)\end{array}$ & 140.9 & $<0.001$ \\
\hline HEALTH CHECK UPS & 4 & $\begin{array}{c}1508 \\
(377 x 4)\end{array}$ & $\begin{array}{c}732 \\
(48.5) \\
\end{array}$ & $\begin{array}{c}879 \\
(58.3)\end{array}$ & 28.4 & $<0.001$ \\
\hline $\begin{array}{c}\text { GROWTH } \\
\text { MONITORING }\end{array}$ & 2 & $\begin{array}{c}754 \\
(377 x 2)\end{array}$ & $\begin{array}{c}626 \\
(83.0)\end{array}$ & $\begin{array}{c}674 \\
(89.4)\end{array}$ & 12.32 & $<0.001$ \\
\hline REFERRAL SERVICES & 1 & $\begin{array}{c}377 \\
(377 x 1)\end{array}$ & $\begin{array}{c}264 \\
(70.0)\end{array}$ & $\begin{array}{c}297 \\
(78.8)\end{array}$ & 7.131 & 0.003 \\
\hline
\end{tabular}




\begin{tabular}{|c|c|c|}
\hline & $\begin{array}{c}\text { No. of AWWs (\%) } \\
\text { (Pretest) }\end{array}$ & $\begin{array}{c}\text { No. of AWWs (\%) } \\
\text { (Posttest) }\end{array}$ \\
\hline Score $>7.5$ & $235(62.3 \%)$ & $340(90.2 \%)$ \\
\hline Score $<7.5$ & $142(37.7 \%)$ & $37(9.8 \%)$ \\
\hline \multicolumn{2}{|c|}{ Table 2: Knowledge assessment score of AWWs pre and post training } \\
\hline
\end{tabular}

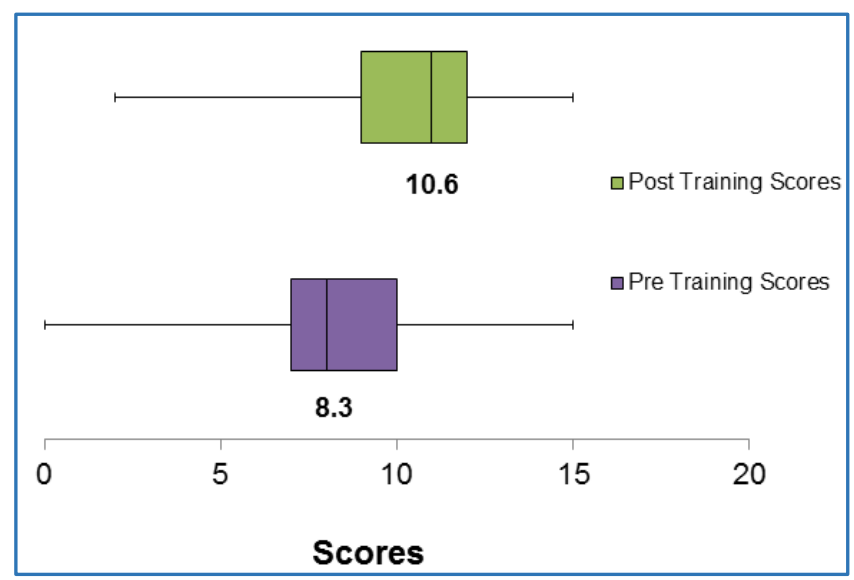

Fig. 1: Box Plot showing pre and post training scores

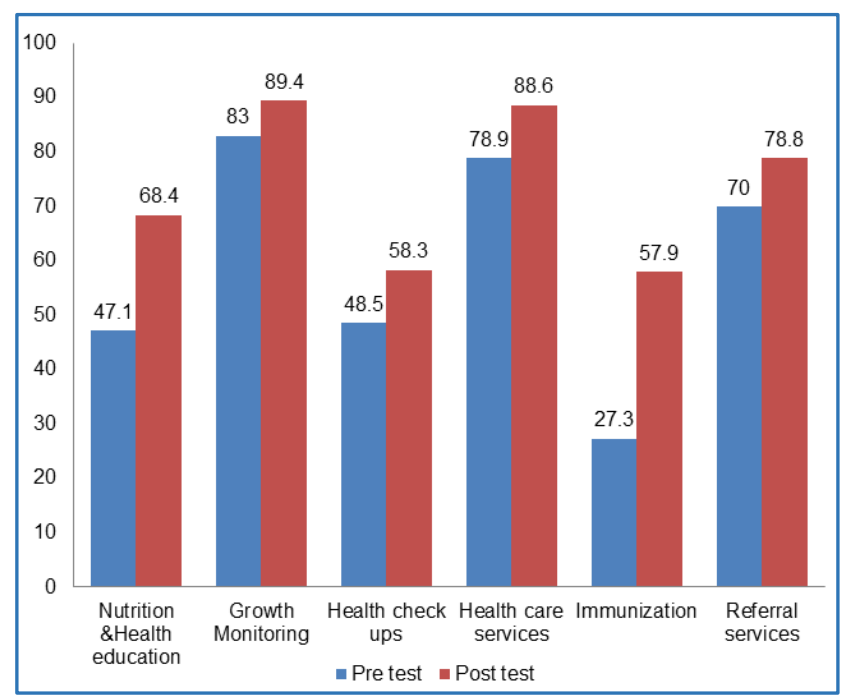

Fig. 2: Improvement in the knowledge of AWWs after training

\section{DISCUSSION}

The prevalence of underweight children is a key indicator of progress towards the Millennium Development Goal (MDG) of eradicating extreme poverty and hunger by 2015 . However, it appears that economic growth alone, though impressive, will not reduce malnutrition sufficiently to meet the MDG nutrition target. If this is to be achieved, difficult choices about how to scale up and reform existing nutrition programs or introduce new ones have to be made by the government of India and other agencies involved in nutrition in India.[6] recognizing the need for early intervention to ensure the development of a young child's body, mind and intellect to its maximum potential, the Government of India started Integrated Child Development Services (ICDS), a centrally sponsored scheme which is a step towards responding to the child's needs in a comprehensive and holistic perspective.[1]

In the present study, AWWs were given training regarding the various services provided by them to the beneficiaries. They were found to have the best knowledge about the component of growth monitoring (83\%), while least about immunization (27.3\%) (Table 1), whereas Patil et al.[4] reported that AWWs had the best knowledge about the component of nutrition and health education (70\%), while least about supplementary nutrition (31.9\%).

Bhasin et al.[7] in their study on Knowledge of Anganwadi workers in Delhi revealed that $99 \%$ had adequate knowledge about the significance of the growth charts that indicate different grades, while 17-30\% knew the correct Mid-Upper Arm Circumference (MUAC) for an optimally nourished child aged 2 and 4 years.

Gopaldas et al.[8] observed from their study that $87 \%$ of the ICDS functionaries could interpret growth charts. These findings were comparable with the findings of the present study.

As per the findings of the present study, $62.3 \%$ of AWWs had a knowledge assessment score of above $50 \%$ as per the proforma provided. The proportion of AWWs having a knowledge assessment score of above $50 \%$ increased to $90.2 \%$ after the training (Table 2). However, Patil et al.[4] reported that $81.63 \%$ of AWWs had a knowledge assessment score of above $50 \%$ as per the questionnaire provided.

In the present study, the mean pretest score was $8.3 \pm 2.5$ and the mean post test score was $10.6 \pm 2.3$ ( $p=0.000$ ) (Fig. 1). Improvement in knowledge was seen in all categories of questions, which included health care services; immunization; nutrition and health education; health check-ups; growth monitoring and referral services (Fig. 2).

Halder et al.[9] in their study in rural West Bengal reported that performance of AWWs can be improved by proper training. Sharma et al.[10] found that AWWs who had completed 9-11 refresher trainings had highest score and those who had completed 3-5 refresher trainings had lowest score in nutrition knowledge.

\section{CONCLUSIONS}

Training of AWWs helps in effectively achieving the objective of the Integrated Child Development Services Scheme and should be considered important for its success. The findings of present study suggest that knowledge of AWWs significantly improved after the training. Thus, refresher training programmes should regularly be conducted for improving the knowledge of grass-root level health workers to ensure provision of good quality services.

\section{REFERENCES}

1. Three Decades of ICDS-An Appraisal. National Institute of Public Cooperation and Child Development (NIPCCD), 2006. Available from:

http://nipccd.nic.in/reports/icdsvol3.pdf.

[Last accessed on 2015 November 20].

2. Integrated Child Development Services (ICDS) Scheme. New Delhi: Ministry of Women and Child Development, Government of India. Available from: http://www.arnec. net/practice/integrated-child-development-servicesicds scheme-ministry-women-child-development-govtindia/. [Last accessed on 2015 October 19]. 
3. National Consultation to Review the Existing Guidelines in ICDS Scheme in the Field of Health and Nutrition. Indian Pediatr 2001;38:721-31.

4. Patil SB, Doibale MK. Study of profile, knowledge and problems of Anganwadi Workers in ICDS blocks: a cross sectional study. Online J Health Allied Scs. 2013;12(1). Available from: http://www.ojhas.org/issue46/2013-21.html. [Last accessed on 2015 November 28].

5. Lemeshow S, Hosmer DW, Klar J, et al. Adequacy of Sample Size in Health Studies. England: John Wiley \& Sons; 1990:1, 42.

6. Gragmolati M, Bredenkamp C, Dasgupta M, et al. ICDS and persistent under-nutrition: strategies to enhance the impact. Economic and Political Weekly 2006;1193-1201. Available from: http://eledu.net/rrcusrn_data/ICDS\%20and\%20Persist ent\%20Undernutrition.pdf. [Last accessed on 2015 November 27].
7. Bhasin SK, Kumar R, Singh $\mathrm{S}$, et al. Knowledge of Anganwadi workers about growth monitoring in Delhi, Indian Pediatr 1995;32:73-6.

8. Gopaldas T, Christian PS, Abbi RD, et al. Does growth monitoring work as it ought to in countries of low literacy? J Trop Pediatr 1990;36:322-327.

9. Halder A, Ray S, Biswas R, et al. Effectiveness of training on infant feeding practices among community influencers in a rural area of West Bengal. Indian J Public Health 2001;45:51-6.

10. Sharma B, Jain S. Impact of ICDS Trainings on Nutritional Knowledge of Anganwadi Workers. Asian Resonance 2014;4:221-25. 